\title{
Economic Geography and Regional Production Structure: An Empirical Investigation
}

\author{
by \\ Donald R. Davis \\ Harvard University, Federal Reserve Bank of New York, and NBER \\ and \\ David E. Weinstein \\ University of Michigan and NBER
}

May 1997

This Draft: March 1998

Correspondence to David E. Weinstein, School of Business Administration, University of Michigan, Ann Arbor, MI 48109. Phone: Davis (617) 496-6416, Weinstein (313) 936-2866. Fax: (617) 495-8570. e-mail: ddavis@fas.harvard.edu, weinstei@umich.edu

Donald Davis is grateful to the Harvard Institute for International Development for funding for this project. Trevor Reeve once again provided first-rate research assistance. The views expressed in this paper are those of the authors, and not those of supporting institutions, the Federal Reserve Bank of New York or the Federal Reserve System. 


\section{Economic Geography and Regional Production Structure: An Empirical Investigation}

\section{ABSTRACT}

There are two principal theories of why countries or regions trade: comparative advantage and increasing returns to scale. Yet there is virtually no empirical work that assesses the relative importance of these two theories in accounting for production structure and trade. We use a framework that nests an increasing returns model of economic geography featuring "home market effects" with that of Heckscher-Ohlin. We employ these trade models to account for the structure of regional production in Japan. We find support for the existence of economic geography effects in eight of nineteen manufacturing sectors, including such important ones as transportation equipment, iron and steel, electrical machinery, and chemicals. Moreover, we find that these effects are economically very significant. The latter contrasts with the results of Davis and Weinstein (1996), which found scant economic significance of economic geography for the structure of OECD production. We conclude that while economic geography may explain little about the international structure of production, it is very important for understanding the regional structure of production. 


\section{Introduction}

Why is there trade? This is a fundamental question for international economists. And it is equally so for those who consider trade across regions. Theory has provided two principal answers: comparative advantage and increasing returns. Comparative advantage holds that trade across geographical units arises to take advantage of inherent differences. Increasing returns says that trade arises to take advantage of scale and variety gains from specialization.

While theorists have devoted great energy to developing myriad models of comparative advantage and increasing returns, empirical research has had next to nothing to say about the relative importance of these two forces in driving world trade. ${ }^{1}$ At one time, researchers might have pointed to the large volume of intra-industry trade or of North-North trade as confirming the importance of increasing returns. Yet closer examination has proven that these phenomena do not distinguish the increasing returns theory from that of comparative advantage. ${ }^{2}$

Renewed hope for distinguishing the theories arises if we restrict ourselves to the class of increasing returns models that Krugman (1991) has labeled "economic geography." ${ }^{3}$ The defining characteristic of these theories is the interaction of increasing returns and costs of trade. As

${ }^{1}$ In reviewing the empirics of the new trade theory, Krugman (1994, p. 23) asks: "How much of world trade is explained by increasing returns as opposed to comparative advantage? That may not be a question with a precise answer. What is quite clear is that if a precise answer is possible, we do not know it."

${ }^{2}$ See Chipman (1992), Davis (1995, 1997), and Deardorff (1996).

${ }^{3}$ The reader should note that the usage of the term "economic geography" in this paper refers specifically to the class of models deriving from Krugman $(1980,1991)$ that interact trade costs and increasing returns in a monopolistic competition framework. As Krugman acknowledges in the latter work, there is a long tradition of work in the more general field referred to by the same name. 
Krugman (1980) showed, this does allow one to identify a critical test distinguishing a world of comparative advantage from one with increasing returns. In a world of comparative advantage, unusually strong demand for a good, cet. par., will make that good an import. In a world with increasing returns, typically each good will have only one site of production. When there are trade costs, a country with unusually strong demand for a good makes that an excellent site to locate production, hence makes that country the exporter of that good. These "home market effects" of demand on trade patterns thus provide a key feature to distinguish a world of comparative advantage from one of increasing returns.

In Davis and Weinstein (1996), we made this search for home market effects the centerpiece of our effort to distinguish the two theories. We noted that the home market effect has an equivalent characterization as a "magnification effect" from idiosyncratic components of demand to output. We then applied this to explain the structure of OECD production. Our null hypothesis was that the conventional Heckscher-Ohlin model explains production structure at the 4-digit ISIC level. The alternative hypothesis was that Heckscher-Ohlin explains only the broad industrial structure of production in these countries at the 3-digit ISIC level, and that this must be augmented with a model of economic geography to account for the finer 4-digit production structure. Within this overarching structure, we identify three possibilities: a frictionless world (comparative advantage or IRS); comparative advantage with positive trade costs; and economic geography.

Our results did not support the proposition that economic geography plays an important role in determining the structure of OECD production. The data strongly rejected a frictionless model, since in such a model demand would have no influence on the location of production. Yet 
the results also rejected the economic geography framework in favor of a model of comparative advantage with trade costs. Some specifications did indicate significant economic geography effects in a number of important industries. However, all specifications which allowed for inclusion of factor endowments as predictors of fine production structure show that the economic geography effects were not robust.

The same question that we ask of countries can be asked of sub-units of countries: Why do regions trade? This is an important and fascinating problem in its own right. Moreover it promises to yield insights of broader applicability. From a theoretical standpoint, we should expect that the same basic forces are at work in the regional and international cases. However, from an empirical standpoint, there is no necessary reason that the answers of their relative importance be the same. It is perfectly conceivable that economic geography could have little influence on the structure of production across countries, yet be very important in explaining the structure of production across regions within a country. This could arise, for example, due to lower interregional trade costs, which theory suggests should strengthen economic geography effects. Thus an investigation that examines the trade of regions may provide the best hope for identifying such effects, and so also provide a favorable experiment to distinguish the microeconomic stories underlying the comparative advantage and economic geography approaches. 


\section{Theoretical Framework}

\subsection{A Regional Approach}

The seminal theoretical contribution underlying our work is Krugman's (1980) model of the "home market effect." In Davis and Weinstein (1996), we showed how to nest his model of economic geography with a model of comparative advantage, the aim being to identify and estimate the importance of such home market effects on OECD production structure. Since the basic theoretical framework in the present paper follows that developed in our earlier work, we will here provide a more compact presentation. However, there are some important issues that must be addressed in moving from an international to a regional setting before we turn to the specifics of our framework.

A conventional contrast between international and regional economics is the greater degree of factor mobility across regions within a country than across countries. This could in principle be very important. Large countries or regions have highly diversified products available without trade costs, so tend to have low price indices. Under certain conditions, large countries may be desirable locations for producers to locate, so they may tend to pay high wages. As well, if some of the differentiated goods themselves serve as inputs to production of differentiated goods, then labor may be more productive in large economies, again tending to raise wages there. All of these suggest that large countries or regions may also attract large numbers of immigrants, tending to empty national or international hinterlands. The greater mobility of factors across regions within a country tends to raise the salience of this issue. [See Krugman $(1980,1991)$ and Krugman and Venables (1995)]. 
Of course, the extensive literature on economic geography has considered at length the tensions between these pressures for concentration and the counteracting pressures for dispersion of economic activity. We choose to sidestep these issues, even as we recognize their importance. We will assume that within the economic geography section of our model, there are in fact some countervailing forces at work that prevent all economic activity from locating on a single point without inquiring the nature of those forces.

We will assume that the economy is in equilibrium. If this is so, then imposing a further condition that factors are not allowed to move ex post will not disturb the nature of the equilibrium. In other words, we are going to treat the regional model as a special case of the international model in which the specific combination of centrifugal and centripetal forces are such that in equilibrium no one would migrate even if they could. The legitimacy of treating a model of regions as if it were a model of countries depends on the questions one addresses. Clearly, the comparative statics of the two models will not be the same. However, our interest is precisely in the static equilibrium, which we believe justifies this approach.

\subsection{Previous Empirical Studies}

The role that scale economies, internal or external, play in production has been an important topic in a wide range of contributions from the regional economics literature [e.g. Sveikauskas (1975), Nakamura (1985), Henderson (1986), Sveikauskas, et al. (1988), Henderson, Kuncoro, and Turner (1995), and Glaeser et al. (1991) ]. These studies have typically searched for the existence of economies of scale or spillovers by estimating production functions or growth specifications with aggregate industry- or city-size variables on the right-hand side. 
The present study differs from the regional contributions in two important respects. The first is that we articulate our empirical specification from a general equilibrium perspective. The second is that within our general equilibrium framework we are able to identify precise null and alternative hypotheses. The focus on general equilibrium is valuable because it allows us to draw on the wealth of analytic results from the international trade literature. In the present study, it allows us to focus on a particularly surprising result (discussed more fully below) known as the "home market effect."

The full specification of null and alternate hypotheses is valuable, since it allows us to be precise about which hypotheses may be distinguished by the evidence. This is particularly important when searching for evidence of scale economies, as these may easily be confounded with omitted factors in regressions of industry output on aggregate regional variables, such as city size or employment. This difficulty common to many of the regional studies is voiced, for example, in Ellison and Glaeser's (1997, p. 897) conclusion that their own "analysis of the mean concentration of industries [the principle dependent variable in their study] . . is compatible with a pure natural advantage model, a pure spillover model, or models with various combinations of the two factors."

The combination of a general equilibrium perspective with the explicit specification of a null and alternative hypothesis is particularly important in comparing our study with related work in the regional literature. An example is the suggestive work of Justman (1994), which also considers a variant of the Linder hypothesis. Justman approached the problem by calculating industry correlations between supply and demand across regions, and then regressing these correlations on industry characteristics. Justman argued that in industries in which the Linder 
hypothesis is valid there should be strong correlations between supply and demand. Our study, focused on home market effects, imposes a more stringent test on the data — not only must supply and demand be correlated, but demand must move supply more than one-for-one.

One might reasonably ask whether our more stringent test is justified or whether one might want to settle for correlations as in the Justman study. To understand this, we must return to the distinguishing prediction of the Linder hypothesis. Virtually any model with trade costs will have the feature that (cet. par.) local demand and supply are correlated. The critical feature of the Linder hypothesis is that demand deviations cause more-than-proportional supply responses. Thus it can be problematic if one focuses simply on correlations instead of magnitudes. Suppose that a demand deviation of ten causes output to rise by one but that the observed data is very tightly distributed around a line of slope one-tenth. The Linder hypothesis is clearly not valid, but the correlation might be quite high. Similarly, if a demand deviation of one caused output to move by ten, but the data are very noisy, one would have a low correlation but clear evidence of the Linder hypothesis. In other words, in order to test for the home market effects characteristic of the Linder hypothesis, one cannot search simply for correlations between supply and demand. Rather one must focus on the magnitude of the relationship. This forms the intuition for our tests which we explain more formally in the next section.

2.3 Economic Geography, Comparative Advantage, and the Home Market Effect This section outlines the key theoretical insight underlying our empirical work. Building on an insight from Linder (1961), Krugman (1980) posed a simple question: Can idiosyncratically 
high demand for a good in a country or region, ceteris paribus, make that good an export? It is

worth considering his intuitive argument before developing the formal models:

In a world characterized both by increasing returns and by transportation costs, there will obviously be an incentive to concentrate production of a good near its largest market, even if there is some demand for the good elsewhere. The reason is simply that by concentrating production in one place one can realize the scale economies, while by locating near the larger market, one minimizes transportation costs. This point - which is more often emphasized in location theory than in trade theory - is the basis for the common argument that countries will tend to export those kinds of product for which they have relatively large domestic demand. Notice that this argument is wholly dependent on increasing returns; in a world of diminishing returns, strong domestic demand for a good will tend to make it an import rather than an export. (1980, p. 955, italics added).

This role for idiosyncratically high demand to lead a good to be exported — the "home market effect" - is our central focus. Its value from an empirical standpoint is that, conditional on costs of trade, it provides a clear contrast between the diminishing returns, comparative advantage theory, and that of increasing returns and economic geography.

Krugman develops a special case of the Dixit-Stiglitz model of monopolistic competition. The crucial departure from Krugman (1979) is the introduction of iceberg costs of trade between economies. The particular example that he works with assumes that there are two types of consumers in the world, each of which demands only one of the two classes of differentiated varieties available in the world. He further assumes that the two equal-sized economies have the consumers in mirror proportions. Symmetry insures nominal factor price equalization. Wellknown properties of the Dixit-Stiglitz iso-elastic case insure that output per variety is the same for all varieties of both types in each country. The only thing to be determined is how many of each variety are produced in each country. Assume that the majority-type consumers in each country exist in relative proportion $\lambda \geq 1$. Because of trade costs, consumers will demand smaller 
quantities of imported than of locally-produced varieties. Let the ratio of the typical consumption of an imported to a local variety be given by $\sigma<1$. Finally, let the number of varieties produced in a country tailored to the tastes of the majority be given by $\mu$. Krugman (1980) shows that for the range of incomplete specialization,

$$
\mu=\frac{\lambda-\sigma}{1-\lambda \sigma}
$$

If there were no idiosyncratic component to demand, i.e. $\lambda=1$, then each country would produce the same number of varieties of each of the two classes of goods, i.e. $\mu=1$. This is important, since it suggests that the "baseline" composition of production will be similar across countries, absent idiosyncratic demand. However, when there are idiosyncratic elements of demand, $\lambda>1$, then it is easily verified that a country produces a larger number of the varieties preferred by its majority-type consumers, so $\mu>1$.

The home market effect, though, requires a yet stronger result. As noted above, Krugman (1980) asked if idiosyncratically high demand could lead a good to be exported. If high demand is to lead the good to be exported, then production must rise by even more than demand. That is, the home market effect requires that idiosyncratically high demand have a magnified impact on production of the relevant good. These are equivalent statements. From above, and again for the range of incomplete specialization, we see that:

$$
\frac{\partial \mu}{\partial \lambda}=\frac{1-\sigma^{2}}{(1-\sigma \lambda)^{2}}>1
$$


That is, Krugman has shown that precisely this kind of "magnification effect" from idiosyncratic demand to production holds in this model. When we turn to the empirical work, this will provide the foundation for deviations from the "baseline" composition of production.

Weder extends this result to the case in which countries differ in size. His principal result is contained in his Proposition 3: "In the open-economy equilibrium, each country is a net exporter of that group of differentiated goods where it has a comparative home-market advantage.” And a country has a comparative home-market advantage when it has a higher proportion of demanders of one type relative to the other. The insight is simple but powerful. Producers of varieties of the different classes of goods must compete for resources within a market. Absolute market size alone leads all producers to want to locate in the larger market. But the aggregate resource constraint in the large market forces an ordering of priorities. It is intuitively pleasing that it is the relative strength of demand that is in fact the deciding factor in determining the pattern of exports. It is straightforward to derive simple extensions considering separately more countries and more goods, indicating some robustness for the basic home market relation [cf. Davis and Weinstein (1996)].

We have seen that in the world of economic geography, unusually strong demand for a good leads that good to be an export, reflecting the home market effect. This contrasts with the results in a comparative advantage world. As noted above, Krugman (1980) argued that “ . . in a world of diminishing returns, strong domestic demand for a good will tend to make it an import rather than an export." Let us think about the underlying logic in a simple import-demand exportsupply framework. Consider a small idiosyncratic component of demand in a country. In a competitive world with rising marginal opportunity costs, this will be met with additional local 
supply only if the price rises. Will a home market effect arise? Note that with a fixed trade-cost wedge, the local price can rise in equilibrium only if the foreign price rises as well. But if the foreign export supply curve has the conventional slope, then this must also imply larger foreign net exports of this good. Hence the local idiosyncratic demand is met in part by a rise in local supply and in part by greater imports — hence local supply rises less than one-for-one with idiosyncratic demand. If the good in question were non-traded both before and after the demand perturbation, then local supply would rise exactly one-for-one. But unless the foreign export supply curve has a perverse slope, local supply will never rise more than one-for-one with idiosyncratic local demand. That is, in the comparative advantage world, home market effects will not arise.

\subsection{Empirical Specification}

We turn now to translating this theory to an implementable empirical specification. The model of Krugman (1980) cannot be taken directly to data. The one-factor model that he develops is entirely appropriate for theory. But it can be rejected without recourse to data if the suggestion is that endowment differences are not important for the structure of production. Thus, if we are to give Krugman's theory a chance, we will need to build into it a structure in which endowments are allowed to matter at one level of aggregation, and economic geography to matter at a finer level of disaggregation. Such an approach is suggested by the work of Helpman (1981), and this is broadly the course that we take. However, we caution that the literature has not developed the economic geography model in sufficient generality to deal simultaneously with differences in the size of regions, goods, and industries, as well as to allow for differences in input 
composition and demand structure. We cannot fully remedy this shortcoming, but we do believe that the framework we develop presents a highly structured and sensible interpretation of Krugman (1980) that focuses on a central feature of the theory. ${ }^{4}$

In the discussion that follows, it will prove useful to distinguish three levels of production. The broadest level is what we term industries, with each industry composed of many goods. In the empirical section, we will have six industries covering the nineteen goods that form the basis of our analysis. For the case of monopolistic competition, each good will feature many varieties. While the varieties play an important theoretical role as the locus of increasing returns, they are never directly observed.

Let us begin with the comparative advantage theory. Our representative of this class for the purpose of our empirical work is the square Heckscher-Ohlin model. Assume that all regions $r$ of Japan share identical constant returns to scale technologies. Assume as well that these technologies are Leontief. Let there be $F$ factors of production. Let there be $N$ industries with $G_{n}$ goods in industry $\mathrm{n}$. Assume that the total number of goods is the same as the number of primary factors, so $\sum_{n=1}^{N} G_{n}=F$. Assume that the $F \times F$ technology matrix mapping output into factors is invertible, where the inverse is given by $\Omega$. Assume that all regions are diversified in production.

${ }^{4}$ To insist on a fully general model is to condemn the theory never to be considered empirically from a general equilibrium perspective. It will remain, as Krugman (1994, p. 9) noted in reviewing the new trade theory, "an enormous theoretical enterprise with very little empirical confirmation." Hence, in our empirical specification we will take what we see to be the robust core of these results, and make strong identifying assumptions as required to implement the theory. 
Letting the vector of goods output for region $r$ and good $g$ in industry $n$ be $X_{g}^{n r}$ the vector of factor endowments be $V^{r}$, and $\Omega_{g}^{n}$ be the corresponding row of $\Omega$, there is an exact relation:

(1) $\quad X_{g}^{n r}=\Omega_{g}^{n} V^{r}$

In this framework, endowments fully suffice to determine the structure of goods production (i.e. for our most disaggregated observations).

The alternative that we develop is in the spirit of Helpman's (1981) nesting of the Heckscher-Ohlin and simple monopolistic competition models. There endowments served to determine the broad industrial structure of a country while monopolistic competition led to intraindustry specialization. We follow the same division, assuming that Heckscher-Ohlin determines the output by regions of industries, while economic geography determines the output of goods within industries. Let $\mathbf{A}$ be a technology matrix, with $\mathbf{A}_{\mathrm{n}}$ a column reflecting input usage within industry $n$. Within industry $n$, there are $G_{n}$ goods. We assume that demand arises from Dixit-Stiglitz (1977) iso-elastic preferences, and that the elasticity of substitution between varieties of a good is common for all varieties of all goods within an industry. This implies that the equilibrium scale of production of each variety of each good within an industry is common [see Krugman (1980)]. If we further assume that both fixed and marginal costs are in scalar proportion to $\mathbf{A}_{\mathrm{n}}$, then we can take that column as the total input coefficients for a variety of any good in industry $n$. We assume that the coefficients of $\mathbf{A}$ are fixed.

Here, as in Helpman (1981), endowments serve to determine the exact structure of production by industry. This can be expressed as: 


$$
X^{n r}=\sum_{g=1}^{G_{n}} X_{g}^{n r}=\bar{\Omega}^{n} V^{r},
$$

where $\bar{\Omega}$ is an $N \times N$ matrix. However endowments provide no information about a region's production structure within an industry - viz. the goods composition of production within the industry. For example, they tell us which regions have a large textile industry, but not whether this will be occupied producing carpets, rugs, etc.

We now need to specify how the location of goods production within industries is determined for the economic geography specification. Absent idiosyncratic components of demand, regions will divide production across goods within an industry in the same proportion as all other regions. Hence regions with a large industry $n$ will produce absolutely large amounts of all goods within $n$, but cet. par. will have the same composition across goods as regions with a smaller industry $n$. This base level of production of a particular good for a region, which depends on that region's overall commitment to the encompassing industry and to the importance of that good in the aggregate within that industry, is what we will refer to as SHARE.

However, in the spirit of Krugman (1980), we posit that this base level of production of a good must be adjusted to reflect the influences of idiosyncratically high demand. Our specification is influenced by Weder (1995) to focus on differences in the relative importance of a good for the specific region relative to all the regions taken together. The magnitude of this influence is, of course, also influenced by that region's total commitment of resources to the industry of interest. This will give rise to a variable that we term IDIODEM. This will play a key role when we turn to 
hypothesis testing, since the economic geography framework predicts that the responsiveness of goods production to movements in IDIODEM will be more than one-to-one.

We can state this hypothesis first in a general form. Let $\gamma_{g}^{n r} \equiv \frac{X_{g}^{n r}}{X^{n r}}, \delta_{g}^{n r} \equiv \frac{D_{g}^{n r}}{D^{n r}}$, and ROJ stand for the rest of Japan (except region r). Then goods production is modeled as:

$$
X_{g}^{n r}=f\left(\gamma_{g}^{n R O J} X^{n r},\left(\delta_{g}^{n r}-\delta_{g}^{n R O J}\right) X^{n r}\right)
$$

where $D$ denotes absorption in either the region, $r$, or Japan as a whole, $J$, and the first derivatives are expected to be non-negative. The first term in $f$ captures the tendency for each region to produce the same relative shares of each good as other regions. Specifically, we postulate that a region's output of any good, $X_{g}^{n r}$, is going to be centered around the product of: (a) The share of that good in that industry's output for the rest of Japan; and (b) A scale term reflecting that industry's total size within the region, $X^{n r}$. The second term in $f$ measures the demand deviation. If all regions demanded the same share of each good, this term would equal zero. If a good comprises a greater (smaller) share of demand within an industry, however, this term will be positive (negative) indicating that the region is an idiosyncratically high (low) demander of that good. Again this is scaled by region r's output in industry $n$.

We will estimate a linear of version of (4) presented below:

$$
X_{g}^{n r}=\alpha_{g}^{n}+\beta_{1} \gamma_{g}^{n R O J} X^{n r}+\beta_{2}\left(\delta_{g}^{n r}-\delta_{g}^{n R O J}\right) X^{n r}+\epsilon_{g}^{n r}
$$

or equivalently

$$
X_{g}^{n r}=\alpha_{g}^{n}+\beta_{1} \operatorname{SHARE}_{g}^{n r}+\beta_{2} \text { IDIODEM } M_{g}^{n r}+\epsilon_{g}^{n r}
$$


While we believe this exercise is informative, we do not want to stop with estimation of equation $\left(4^{\prime}\right)$. The reason is that such a specification may suffer from an omitted variables bias, as it assumes that endowments play no role in the location of goods production once we know the level of industry output. Thus we estimate a nested model:

$$
X_{g}^{n r}=\alpha_{g}^{n}+\beta_{1} S_{H A R E}^{n r}+\beta_{2} I D I O D E M_{g}^{n r}+\Omega_{g}^{n} V^{r}+\epsilon_{g}^{n r},
$$

We want to verify that the conclusions derived from our earlier tests are robust to allowing endowments to matter for output at a finer level of production. The structure that we have placed on the analysis enables us to directly test the hypothesis of whether economic geography can improve our understanding of production patterns at the goods level relative to the hypothesis that all production is determined by endowments.

A few more words are in order about the specification. If the production of goods within a region is proportional to production of these goods in the rest of Japan, then SHARE will equal the expected level of production of a good given output at the industry level. In the specification without endowments, one should expect the coefficient on SHARE to be unity.

Our main interest is in testing a null that Heckscher-Ohlin predicts the level of goods output against an alternative that an augmented economic geography model does so. However, it will prove informative to postpone this test and first consider directly several hypotheses concerning equation (4"). The key is the interpretation of the coefficient $\beta_{2}$, for which we distinguish three hypotheses. In a frictionless world (comparative advantage or IRS), the geographical structure of demand should have no influence of production patterns, so $\beta_{2}=0 .{ }^{5}$ In a

${ }^{5}$ The fact that the home market effect distinguishes the theory only when there exist costs of trade is of little practical import. It is true that, for simplicity, the theoretical literature in both 
comparative advantage world with trade costs, the geographical location of demand does matter.

But so long as import demand and export supply curves have the conventional slopes, the response of local supply to idiosyncratic components of demand should be at most one-to-one.

Finally, as discussed previously, in the presence of economic geography, we expect the response of local production to idiosyncratic components of demand to be more than one-to-one. Summarizing:

\section{Interpretation of $\beta_{2}$}

1) $\quad \beta_{2}=0: \quad$ Frictionless World (Comparative Advantage or IRS)

2) $\quad \beta_{2} \in(0,1]: \quad$ Comparative Advantage with Trade Costs

3) $\quad \beta_{2}>1: \quad$ Economic Geography

\section{Empirics}

\subsection{Econometric Issues}

Equations (2) and $\left(4^{\prime}\right)$ can be estimated at various levels of aggregation, separately or as a system of seemingly unrelated regressions. The latter yields maximum power to discern the average impact of economic geography in our sample. Alternatively, we can allow the coefficients on the parameters to vary at the goods or industry level.

Direct estimation of (4') is not possible because of a simultaneity problem. Because $X_{g}{ }^{n r}$ is an element of $X^{n r}$ one cannot treat them as independent observations. Davis and Weinstein (1996)

frameworks has traditionally ignored costs of trade. This is relatively innocuous in the case of comparative advantage, much less so for increasing returns. In any case, we will see that our data strongly reject the zero-trade-cost model, as is consistent with the recent work of McCallum (1995) and Engel and Rogers (1996). 
show however, that if we assume that factor endowments drive aggregate production, then we will have a theoretically consistent set of instruments: factor endowments. In what follows, we therefore always instrument $X^{n r}$ on factor endowments.

Second, there are two types of heteroskedasticity in these data. Errors are likely to be correlated with the size of both regions and industries. These two types of heteroskedasticity can be corrected for by postulating that for each good the error process is of the form given below:

$$
\operatorname{var}\left(\epsilon_{g}^{n r}\right)=\phi_{g}^{n} G D P_{r}^{\theta_{g}^{n}}
$$

where $\phi_{g}{ }^{n}$ and $\theta_{g}{ }^{n}$ are parameters. We corrected for heteroskedasticity by first estimating the system and generating the squared residuals. Following Leamer (1984), We then regressed the $\log$ of this series on the log of regional GDP and then used the fitted values to form our weighting series for the heteroskedasticity correction.

\subsection{Data Issues}

In this section we provide an overview of the data used in the paper (details on the construction of variables are in the appendix). Our data set contains output, endowment, and absorption data for the 47 prefectures/cities of Japan. However, we were concerned that people in the cities of Tokyo and Osaka might be working in the city but living and consuming in an adjacent prefecture, so we were forced to aggregate some of the data. We formed two aggregates: Kanto, out of the city of Tokyo and the prefectures of Yamanashi, Kanagawa, Chiba, and Saitama; and Kinki, out of the prefectures/cities of Hyogo, Kyoto, Nara, and Osaka. This 
reduced our sample to 40 observations, but enabled us to significantly increase the probability that anyone within a region consumed largely within that region.

Our next problem was how to define industries and goods. Ideally, we would like to rely on industry classifications based on technological criteria rather than substitutability in demand. Unfortunately, industry classification schemes are typically based upon the latter more than the former. There is some evidence that standard industry definitions do contain information about production technologies [Maskus (1991)]. However, since we had access to the Japanese technology matrix, we decided that we could provide more theoretically sensible classifications than those typically found in statistical annuals.

In earlier work [Davis, Weinstein, et al. (1997)] we had constructed a technology matrix for Japan. This matrix enabled us to have direct information on college, non-college, and capital usage for 30 sectors. Of these 30 sectors, we dropped eight non-tradable goods sectors and two agricultural sectors (agriculture, forest, and fishery products and processed foods). We felt it necessary to drop the agricultural sectors because large-scale Japanese industrial policy interventions, such as price supports, marketing boards, tax breaks, subsidies, zoning laws, etc. significantly distort demand and supply in these sectors. Indeed, this accounts for the fact that in our data 13 per cent of private land in the city of Tokyo (i.e. not the greater Tokyo metropolitan area) is farmland. Finally we also dropped mining since it is obviously an endowment-based sector.

The nineteen sectors that we eventually used are reported in Table 1. Davis and Weinstein (1996) argued that in international data one can reject the economic geography specification in favor of the Heckscher-Ohlin specification for these industry categories. However, as we have 
suggested earlier, there is reason to be more optimistic that we can identify home market effects in Japanese data. Bernstein and Weinstein (1997) argue that the reason for the good fits in international data is the interaction between transaction costs and Heckscher-Ohlin effects. These authors demonstrate that on Japanese data, where transactions costs are small, there is substantial production indeterminacy at this level of aggregation. This has two important implications for our work. First, since endowments do not predict output as well on regional data as on international data, there is more latitude for other factors, such as economic geography, to determine regional production. Second, the fact that transportation costs are substantially smaller between regions means that the observed economic geography effects will be stronger [cf. Krugman (1991)]. Both of these reasons suggest that we should be more optimistic about finding a role for economic geography in determining regional production.

In some of the exercises that we will carry out, aggregation of goods into industries may in principle matter a great deal. The theory literally holds that all varieties of all goods within an industry use common input coefficients. Obviously this is too much to hope for with real data. So we are required to aggregate the goods into industries in a way that respects the underlying theoretical requirement that goods within an industry use similar input coefficients. Unfortunately, in a world with more than two inputs, there is no theoretically compelling manner for performing this aggregation. Hence we took a pragmatic approach of considering aggregation based on factor-intensity ratios, taking two factors at a time. Unfortunately, although ranking sectors by college to non-college ratios and capital to non-college ratios yields similar orderings, one obtains radically different orderings if one looks at capital to college ratios. Ultimately, we decided to form industry aggregates on the basis of college to non-college factor ratios, because this scheme 
yielded the most plausible aggregates. The other aggregations schemes, especially the capital to college scheme, had enormous outliers and produced very odd mixes of industries.

We calculated the ratio of college to non-college workers in each sector and then divided the 19 goods into six industry aggregates based on the similarity of these ratios. The last columns of Table 1 present these aggregates. Larger numbers indicate an industry composed of goods with higher factor-intensity ratios. The commodity groupings for the college/non-college aggregation scheme seem quite sensible, although there are a few anomalies, e.g. leather in industry 5.

Table 2 presents sample statistics for our data set using the college/non-college aggregation scheme. These reveal that the typical good constitutes about one-third of the typical industry and that there is substantial variation in idiosyncratic demand, which is important because we need variation in the latter to drive the home market effects.

\subsection{Estimating the Heckscher-Ohlin Production Model}

Since our theoretical framework requires us to find a level of aggregation for which factor endowments drive aggregate production, it is reasonable to ask whether our aggregation scheme enables us to explain much of the variance at the three-digit level. Table 3 presents results of estimating equation (1) for our sample of 40 regions. What is striking in our results is the fact that fits of the regressions are quite high. Indeed, our results indicate that, on average, factor endowments can explain almost 80 per cent (0.786) of the variation of our aggregates.

It is worth remembering, however, that there are two sources of variation in these data. One source is pure size-based variation: larger regions produce more output. If all of our explanatory power came from this source of variation, it would be somewhat disturbing, since one 
would like to believe that endowments should tell us something about the relative sizes of industries within regions. In other words, we would like endowments to also tell us about crosssectional variation within regions of similar size. One way to eliminate this size-based variation and examine the cross-sectional variation is to force the exponent on GDP to equal two in our heteroskedasticity correction. This is equivalent to estimating a version of equation (2) in which both sides have been deflated by GDP. When we estimated this version of the equation we obtained an average $\mathrm{R}^{2}$ of 0.4 . This suggests that even after controlling for size based variation, endowments explain almost half of the variance of aggregate output. Furthermore, our data revealed that endowments had a more difficult time explaining more disaggregated output levels. Using the same specification, we only obtained an average $\mathrm{R}^{2}$ of only 0.3 when we ran the same specification on the most disaggregated data. This is consistent with the theoretical notion that the Heckscher-Ohlin framework performs better using aggregates of industries with similar factor intensities than using disaggregated data.

Overall, our results suggest that endowments and output are highly correlated on regional data, and we have therefore established that the idea that endowments matter in determining the location of production is a credible null hypothesis.

\subsection{Testing for Home Market Effects}

Before presenting our regression evidence, we begin by plotting our data. Our formulation of the theory, given in equation (4"), suggests that we have a multivariate relationship between the variables. If , however, we impose that $\beta_{1}$ equals 1 , divide through by industry level output, and carry the SHARE variable over to the left-hand side, we obtain 


$$
\gamma_{g}^{n r}-\gamma_{g}^{n J}=\frac{\alpha_{g}^{n}}{X^{n r}}+\beta_{2}\left(\delta_{g}^{n r}-\delta_{g}^{n J}\right)+\tilde{\epsilon}_{g}^{n r}
$$

The left-hand side of this equation measures how the share of industry output within a prefecture deviates from that share for the rest of Japan, while the term in parentheses indicates the deviation in absorption. In Figure 1 we refer to these two variables as the "Production Deviation" and the "Absorption Deviation."

If economic geography has some role to play in these data one should expect to see absorption deviations produce more than one-for-one movements in output. This would result in a line with a slope of more than one. On the other hand if comparative advantage determined production, then one would expect to see a line with a slope of less than one. As we see in Figure 1, the slope of the fitted line is 1.7. This suggests economic geography effects. Based on the slope of the fitted line in this figure, a rise in a prefecture of idiosyncratic demand leads net exports to rise by 70 per cent of the increment to local demand.

These results are surprising in light of our earlier work on international data. We conducted a similar experiment for the OECD using 2- and 3-digit ISIC classifications (which approximately correspond to the level of aggregation here). In the international data, the fitted line was significantly below the diagonal at this level of aggregation, with a slope of only 0.66 . In other words, international data revealed no economic geography effect at this level of aggregation, and only a very weak relationship at greater levels of disaggregation.

Although this graph is quite suggestive that economic geography might matter for regional specialization, regression analysis will allow us to examine these relations more precisely. We begin by estimating equation $\left(4^{\prime}\right)$. The results from this exercise are presented in Table 4 . When 
we do not include factor endowments in the specification, our econometric results confirm the general impression of the data that we obtained in Figure 1. Although the coefficient is slightly smaller, its value of 1.42 is clearly in the range of economic geography.

The results presented thus far have examined economic geography against a very weak null hypothesis: viz. that factor endowments do not matter at all at the goods level. Davis and Weinstein (1996), however, show that factor endowments play an important role in determining production at this level of aggregation on international data. This suggests that by leaving out factor endowments from our estimating equations we may be creating an omitted-variables bias. Consider the following possibility. We know that an important component of absorption is demand for intermediate goods. Demand for intermediates is determined by the production of final goods, but, if one believes in equation (1), production of the latter is driven by endowments. This implies that demand for intermediates may be driven by endowments. In other words, if one believes that endowments determine production, then it would not be surprising to find that there is a correlation between production and absorption because both are driven by endowments.

The obvious solution is to estimate equation (4") since it includes factor endowments on the right-hand side. The results of this exercise are presented in the second column of Table 4. Interestingly, this causes the coefficient on IDIODEM to decline to $0.9 .^{6}$ This implies that once we account for factor endowments, it no longer is the case that movements in demand produce

${ }^{6}$ The coefficient on SHARE typically was negative in specifications with endowments. This is largely due to the high degree of multicollinearity between this variable and the endowments. Since SHARE simply picks up industry size effects that can easily be captured by endowments, we experimented with omitting the variable and constraining it to equal one. These experiments did not qualitatively alter our results. 
more than proportionate movements in production. In other words, this specification rejects economic geography.

This result is troubling, especially in light of our earlier work. On international data, we also rejected the economic geography specification, but when we did so in the specification with factor endowments, we obtained a coefficient on IDIODEM of 0.3. This implies that in international data, on average less than one-third of any deviation in demand was met by higher domestic production, the rest being met by imports. This result makes sense in light of the existence of international transaction costs which theoretically can cause demand and production to covary. What is more puzzling is that if one believes that comparative advantage drives production then one should also believe that in regional data, where transportation costs are presumably lower, one should obtain an even smaller coefficient on IDIODEM. Instead we have a coefficient that is too large to plausibly be generated by comparative advantage and transport costs, but too small to signal economic geography.

One explanation for these results is that not all sectors are composed of monopolisticallycompetitive industries. Suppose that only a few of our aggregates actually contain sectors exhibiting increasing returns. Then our system of equations would be pooling together industries in which the coefficient on IDIODEM is greater than unity with sectors in which the coefficient is less than unity. This pooling could be the explanation for a coefficient that is too high to plausibly describe a comparative advantage world, but too low to lead us to believe that economic geography matters.

Fortunately, it is straightforward to modify our theory to address this problem. Assume that some of our aggregates are composed entirely of constant returns to scale sectors and others 
of increasing returns to scale sectors. Then the correct test would be to run equation $\left(4^{\prime \prime}\right)$ separately for each aggregate. This should result in aggregates without monopolisticallycompetitive sectors exhibiting low coefficients on IDIODEM, but sectors with increasing returns producing coefficients over unity. The results from this exercise are presented in Table 5. In the three least skilled-intensive aggregates, we detect no significant economic geography effect. However, in the more skill-intensive aggregates 4 and 5 we find a coefficient that is larger than unity and significant at the 10 and 5 per cent levels respectively. The fact that these sectors contain such plausible economic geography candidates as general machinery, electrical machinery, transportation equipment, and precision instruments makes it even more believable that economic geography effects may be present in these data.

However, it is also important to focus on economic, not only statistical, significance. While we have been able to detect the presence of economic geography effects, it remains to be seen whether it matters much for production. To assess the latter we consider B-coefficients. These statistics tell us how sensitive production is to movements in idiosyncratic demand. Formally, a ß-coefficient tells us how many standard deviations the dependent variable is predicted to move if the independent variable moves one standard deviation. As discussed by Leamer (1984), these statistics are useful in answering questions regarding which independent variables are important in determining movements in the dependent variable. In earlier work on international data, we found that often even when we could detect economic geography in the sample, this impact was economically small. While we find larger effects in the regional data, they nonetheless remain modest. A one-standard-deviation movement in idiosyncratic demand moves production by 0.22 standard deviations in aggregate 4 , and by 0.09 standard deviations in 
aggregate 5. In other words, knowing the variation in idiosyncratic demand does not provide much information about the variation in production. Indeed, these numbers are not that different than what we found on international data, suggesting that even in the sectors where economic geography matters, the effects are relatively modest.

These results, however, are obviously very sensitive to the aggregation scheme. For example, the inclusion of an unlikely economic geography candidate, leather, in aggregate 5 may dilute the overall impact of economic geography in these data. In fact, while we found that changing the basis of our aggregation scheme had little impact on estimates obtained in the full system, changing the mix of goods within our industry definitions could cause different groups of industries to be labeled as sectors with significant economic geography effects.

One solution to this theoretical and empirical mire is to foreswear aggregation altogether, and allow all coefficients to vary at the goods level. This might be appropriate if, contrary to our initial theoretical specification, the elasticity of substitution between varieties of a good is different for the various goods within an industry. The results from this exercise are presented in Table 6. The coefficient on IDIODEM is significantly larger than unity for eight of the nineteen sectors: textiles, paper and pulp, iron and steel, chemicals, transportation equipment, precision instruments, non-ferrous metals, and electrical machinery. With perhaps the exception of paper and pulp, all of these seem like plausible candidates for monopolistic competition, with textiles, transportation equipment, iron and steel, and electrical machinery providing canonical examples of the power of the economic geography framework [see Krugman (1991)]. Furthermore, our results are robust to whichever aggregation scheme we choose. The variables SHARE and IDIODEM will vary depending on whether we group industries on the basis of college to non- 
college, capital to non-college ratios, or capital to college ratios. However, we found that all of these sectors except paper and pulp were identified as exhibiting economic geography effects regardless of the aggregation scheme.

We can run an additional robustness check to confirm that we are identifying economic geography effects here. We posit that the R\&D-intensity of an industry may be used as a proxy for the increasing returns and monopolistic competition that underlie the economic geography theory. Figure 2 plots our estimated coefficients against sectoral R\&D expenses divided by sales. The correlation is 0.62 , indicating that high $\mathrm{R} \& \mathrm{D}$ is associated with identification of economic geography sectors. In fact, the four most R\&D-intensive sectors are also the four sectors for which we obtain the highest coefficients on IDIODEM.

Once again we confront the issue of economic significance. We repeat our experiment with beta-coefficients, only this time we use the disaggregated results presented in Table 6 . Table 7 reports the $B$-coefficients for the 8 sectors for which we obtained statistically significant economic geography coefficients. For these sectors, economic geography seems quite important. A one standard deviation movement in idiosyncratic demand on average moves production by half a standard deviation. In other words, observed fluctuations in idiosyncratic demand seem to provide a lot of information about production patterns. Furthermore, in the important sector of transportation equipment, these effects are very strong. Although economic geography may not be that important for international specialization, there appears to be strong evidence that it matters for certain sectors on a regional level.

\section{Conclusion}


This paper investigates the existence and importance of economic geography effects in determining production structure for a sample of regions of Japan. Results from this regional work both complement and contrast with those of Davis and Weinstein (1996) based on a sample of OECD countries. Within the hypothesis testing framework developed, the earlier work found scant support for the economic geography framework in the international sample. Moreover, even insofar as it was possible to statistically identify such effects, their economic significance was very minimal.

The regional data prove much more supportive of the economic geography hypothesis. We find statistically significant effects of economic geography for eight of nineteen manufacturing sectors: transportation equipment, iron and steel, electrical machinery, chemicals, precision instruments, nonferrous metals, textiles, and paper and pulp. Moreover, for many of these sectors, the economic geography effects are likewise very significant in economic terms.

Why are the regional effects of economic geography so strong, while the international effects are so weak? We suspect two principal reasons. The first is trade costs: both transport costs and myriad barriers to trade must surely be lower for trade between regions of a country than between countries. In the economic geography framework, lower (but strictly positive) trade costs lead to stronger effects, as this reflects lower implicit protection for production in the relatively smaller markets. The second likely reason is the greater mobility of factors across regions than countries. The suggestion is that such mobility will tend to reinforce the economic geography effects, relieving scarcities in regions favorable on economic geography grounds for production of particular goods. 
How do these new results affect the conclusions of our earlier work regarding the significance of economic geography in determining production specialization within the OECD? They bring our earlier work into sharper focus in two respects. First, our earlier work had found weak evidence of economic geography effects in as many as one-third of the goods that comprise our sample. Since the microeconomic story that one tells at the regional and international level is by and large the same, this strengthens our confidence that we had in fact identified economic geography effects in the international data. The fact that we find the economic significance of economic geography to be greater in the regional data is exactly what one would expect. This likewise gives us greater confidence that our methodology is not inherently biased against finding important economic geography effects. Hence it tends to strengthen our confidence in our earlier finding that economic geography does not matter a great deal in understanding the structure of international production.

The sharp contrast in the economic significance of economic geography effects across regions versus internationally is a strong caution against accepting the view that the boundary between international and interregional economics is on the verge of vanishing due to reductions in border barriers. As such, this reinforces the perspective offered in McCallum (1995) and Engel and Rogers (1996) that national borders continue to matter a great deal. Moreover, the strength of the economic geography effects on the regional data suggest that the if the future holds a time when international trade costs truly do fall to the level of interregional trade costs, then quite substantial international restructuring of industry may be in the offing.

The empirical approach to identifying economic geography effects that we employ in this paper is novel. In order to keep our framework simple, we have set to the side a large number of 
important analytic and empirical questions. These include the roles of absolute market size, forward- and backward-linkages, and "real-world" geography. Naturally, the results reported here should be interpreted with an understanding that many issues in this area remain to be explored.

In sum, economic geography appears to be very important in determining the structure of production across regions of Japan for eight of nineteen manufacturing sector. In contrast to Davis and Weinstein (1996), which in exactly the same framework had shown scant economic significance of economic geography for the structure of OECD production, here we find that it is very important for the structure of regional production. 


\section{References}

Armington, Paul S. (1969) "A Theory of Demand for Products Distinguished by Place of Production," IMF Staff Papers, 16, March.

Ben-Zvi, Shmuel and Elhanan Helpman (1992) “Oligopoly in Segmented Markets," in Gene Grossman, ed. Imperfect Competition and International Trade, Cambridge: MIT.

Bernhofen, Daniel (1995) "Intraindustry Trade and Strategic Interaction: Theory and Evidence," mimeo, Clark University.

Bernstein, Jeffrey and David Weinstein (1997) "Do Endowments Predict the Location of Production? Evidence from National and International Data," mimeo, University of Michigan.

Bowen, Harry P., Edward Leamer, and Leo Sveikauskas (1987) "Multicountry, Multifactor Tests of the Factor Abundance Theory," American Economic Review, v. 77.

Brander, James A. (1981) “Intra-Industry Trade in Identical Products," Journal of International Economics, 11.

Chipman, John S. (1992) "Intra-Industry Trade, Factor Proportions and Aggregation," in Economic Theory and International Trade: Essays in Memoriam, J. Trout Rader, NY: Springer-Verlag.

Davis, Donald R. (1995) “Intra-Industry Trade: A Heckscher-Ohlin-Ricardo Approach,”, Journal of International Economics, 39:3-4, November.

Davis, Donald R. (1997) "Critical Evidence on Comparative Advantage? North-North Trade in a Multilateral World.” forthcoming Journal of Political Economy, October.

Davis, Donald R. and David E. Weinstein, (1996) "Does Economic Geography Matter for International Specialization,” NBER \# 5706, August 1996.

Davis, Donald R., David E. Weinstein, Scott C. Bradford and Kazushige Shimpo (1997) "Using International and Japanese Regional Data to Determine When the Factor Abundance Theory of Trade Works," American Economic Review, June.

Deardorff, Alan V. (1995) "Determinants of Bilateral Trade: Does Gravity Work in a Neoclassical World?" forthcoming in Jeffrey Frankel, ed., Regionalization of the World Economy, Chicago: U. of Chicago and NBER. 
Dixit, Avinash K., and Stiglitz, Joseph E. (1977) "Monopolistic Competition and Optimum Product Diversity," American Economic Review 67 (3), 297-308.

Engel, Charles and Rogers, John H. (1996) "How Wide is the Border?" American Economic Review, December.

Helpman, Elhanan (1981) "International Trade in the Presence of Product Differentiation, Economies of Scale and Monopolistic Competition: A Chamberlin-Heckscher-Ohlin Approach," Journal of International Economics, 11:3.

Krugman, Paul (1979) “Increasing Returns, Monopolistic Competition, and Trade," Journal of International Economics, 9: 4.

Krugman, Paul R. (1980) "Scale Economies, Product Differentiation, and the Pattern of Trade," American Economic Review, 70, 950-959.

Krugman, Paul R. (1984) "Import Protection as Export Promotion," in H. Kierzkowski, ed., Monopolistic Competition and International Trade, New York: Oxford U. Pr.

Krugman, Paul R. (1990) “Introduction,” Rethinking International Trade, Cambridge: MIT.

Krugman, Paul R. (1991) Geography and Trade, Cambridge: MIT.

Krugman, Paul R. (1994) "Empirical Evidence on the New Trade Theories: The Current State of Play," in New Trade Theories: A Look at the Empirical Evidence, London: Center for Economic Policy Research.

Krugman and Venables (1995) "Globalization and the Inequality of Nations," Quarterly Journal of Economics, CX: 4.

Leamer, Edward (1984) Sources of International Comparative Advantage: Theory and Evidence, Cambridge: The MIT Press.

Linder, Staffan Burenstam (1961) An Essay on Trade and Transformation, NY: John Wiley and Sons.

McCallum, John (1995) "National Borders Matter: Canada-US Regional Trade Patterns," American Economic Review, 85:3.

Ricardo David (1951), "On the Principles of Political Economy and Taxation," (The Works and Correspondence of David Ricardo, vol. 1), ed. P. Sraffa, Cambridge: Cambridge U. Pr. 
Rybczynski T.M. (1955) "Factor Endowments and Relative Commodity Prices," Economica, XXII.

Weder, Rolf (1995) "Linking Absolute and Comparative Advantage to Intra-Industry Trade Theory," Review of International Economics, 3:3, October. 
Table 1

Aggregation Scheme

Sector

Textiles

Apparel

Lumber \& Wood

Furniture

Ceramics, Stone, Clay, Glass

Iron and Steel

Paper and Pulp

Rubber

Fabricated Metal Products

Transportation Equipment

Other Manufacturing

Leather \& Leather Products

Non-Ferrous Metals

General Machinery

Electrical Machinery

Precision Instruments

Printing and Publishing

Chemicals

Petroleum and Coal Products
College/Non- Capital/Non-College Capital/College

\section{College}

1

1

1

1

2

2

3

3

3

4

4

5

5

5

5

5

6

6

6
4

2

5

3

5

6

5

4

3

5

4

1

5

3

3

2

2

4

6 
Table 2

Variable
SHARE/Xr
IDIODEM/X
Non-College
College
Capital
Land

Obs

760

760

40

40

40

40
Std. Dev.

0.2113

0.0824

2500886

1063285

13400000

2570

$\begin{array}{rr}\text { Min } & \text { Max } \\ 0.0108 & 0.7746 \\ -0.4037 & 0.4037 \\ 372125 & 14500000 \\ 62628 & 6443185 \\ 1469625 & 79100000 \\ 555 & 16487\end{array}$


Table 3

Aggregated Production on Factor Endowments

(40 Regions, Heteroskedasticity Corrected Estimates)

\begin{tabular}{|c|c|c|c|c|c|c|c|}
\hline & \multicolumn{5}{|c|}{$t$-statistics } & \multirow{2}{*}{\begin{tabular}{|r|}
$F_{.01,5,35}=$ \\
3.6 \\
$F$-Statistic \\
\end{tabular}} & \multirow{2}{*}{\begin{tabular}{|} 
Adjusted \\
$\qquad R^{2}$
\end{tabular}} \\
\hline & Constant & College & 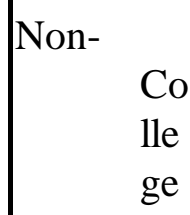 & Capital & Land & & \\
\hline Aggregate 1 & -0.343 & -3.389 & 1.29 & 1.715 & -3.823 & 14.77 & 0.5854 \\
\hline Aggregate 2 & -1.208 & -2.413 & -0.085 & 2.432 & -3.522 & 24.02 & 0.7024 \\
\hline Aggregate 3 & -3.317 & -2.286 & 3.255 & 0.266 & -3.503 & 78.45 & 0.8882 \\
\hline Aggregate 4 & -2.702 & -1.758 & 1.213 & 1.209 & -3.422 & 11.86 & 0.5268 \\
\hline Aggregate 5 & -2.086 & 0.396 & 3.182 & -0.946 & -2.621 & 70.19 & 0.8765 \\
\hline Aggregate 6 & 0.467 & 4.994 & 1.323 & -1.098 & -0.534 & 1192.63 & 0.9919 \\
\hline
\end{tabular}




\section{Table 4}

Seemingly Unrelated Regression Results

Dependent Variable is Production

$\begin{array}{lcc}\text { IDIODEM } & 1.416 & 0.888 \\ & 0.025 & .070 \\ \text { SHARE } & 1.033 & -1.7441 \\ & 0.007 & 0.211 \\ \text { FACTORS } & \text { No } & \text { Yes } \\ \text { Observations } & 760 & 760\end{array}$

(Standard errors are below estimates) 
Table 5

Estimation by Aggregate

Dependent Variable is Output (Std. Errors Below Estimates)

\begin{tabular}{c|c|c|c} 
Aggregate & IDIODEM & SHARE & Obs \\
\hline 1 & 0.1052 & -2.864 & 160 \\
& 0.1628 & 0.9320 & \\
\hline 2 & 1.0320 & -1.6958 & 80 \\
& 0.3328 & 2.2646 & \\
\hline 3 & 0.4272 & -10.681 & 120 \\
& 0.1480 & 1.6466 & \\
\hline 4 & 1.4757 & 2.6239 & 80 \\
& 0.2521 & 0.7825 & \\
\hline 5 & 1.3575 & -3.1882 & 200 \\
& 0.1430 & 0.8202 & \\
\hline 6 & 0.8808 & -0.2538 & 80 \\
& 0.2230 & 0.2766 &
\end{tabular}


Table 6

Disaggregated Estimation

Dependent Variable is Output (Std. Errs. Below estimates)

\begin{tabular}{|c|c|c|c|c|c|}
\hline Industry & IDIODEM & SHARE & Factors & Adjusted R2 & Observations \\
\hline Textile & $\begin{array}{l}3.9532 \\
0.4570\end{array}$ & $\begin{array}{l}0.5932 \\
3.2302\end{array}$ & Yes & 0.8468 & 40 \\
\hline Apparel & $\begin{array}{c}-1.5866 \\
0.2843\end{array}$ & $\begin{array}{c}-24.3909 \\
4.3741\end{array}$ & Yes & 0.5725 & 40 \\
\hline Lumber & $\begin{array}{l}1.0622 \\
0.4440\end{array}$ & $\begin{array}{l}4.1937 \\
1.8351\end{array}$ & Yes & 0.8106 & 40 \\
\hline Furniture & $\begin{array}{l}-0.5538 \\
0.2765\end{array}$ & $\begin{array}{c}-5.1598 \\
1.4389\end{array}$ & Yes & 0.988 & 40 \\
\hline Pulp, paper & $\begin{array}{l}1.9913 \\
0.3150\end{array}$ & $\begin{array}{c}-8.9731 \\
1.7861\end{array}$ & Yes & 0.8917 & 40 \\
\hline Printing & $\begin{array}{l}0.7269 \\
0.2296\end{array}$ & $\begin{array}{l}-0.3423 \\
0.2876\end{array}$ & Yes & 0.9979 & 40 \\
\hline Chemicals & $\begin{array}{l}6.6781 \\
1.2454\end{array}$ & $\begin{array}{l}0.9248 \\
1.1038\end{array}$ & Yes & 0.9928 & 40 \\
\hline $\begin{array}{l}\text { Petrol, Coal } \\
\text { produc } \\
\text { ts }\end{array}$ & $\begin{array}{l}-0.4655 \\
2.3048\end{array}$ & $\begin{array}{l}-6.3220 \\
4.2047\end{array}$ & Yes & 0.9934 & 40 \\
\hline Rubber & $\begin{array}{l}-0.1081 \\
0.1763\end{array}$ & $\begin{array}{l}-24.5223 \\
5.78042\end{array}$ & Yes & 0.8454 & 40 \\
\hline $\begin{array}{l}\text { Leather, leather } \\
\text { produc } \\
\text { ts }\end{array}$ & $\begin{array}{l}0.1643 \\
0.4053\end{array}$ & $\begin{array}{c}-7.1330 \\
1.7866\end{array}$ & Yes & 0.9412 & 40 \\
\hline
\end{tabular}




\begin{tabular}{|c|c|c|c|c|c|}
\hline $\begin{array}{l}\text { Stone, clay, } \\
\text { glass }\end{array}$ & $\begin{array}{l}-0.6454 \\
0.4148\end{array}$ & $\begin{array}{l}-5.0674 \\
2.4824\end{array}$ & Yes & 0.7681 & 40 \\
\hline Iron, steel & $\begin{array}{l}3.9294 \\
0.5613\end{array}$ & $\begin{array}{l}-3.9582 \\
6.2968\end{array}$ & Yes & 0.7663 & 40 \\
\hline $\begin{array}{l}\text { Non-ferrous } \\
\text { metals }\end{array}$ & $\begin{array}{l}1.5932 \\
0.1741\end{array}$ & $\begin{array}{l}2.5509 \\
3.1334\end{array}$ & Yes & 0.962 & 40 \\
\hline Fabricated metal & $\begin{array}{l}-0.8197 \\
1.0820\end{array}$ & $\begin{array}{c}-14.0257 \\
7.0734\end{array}$ & Yes & 0.5972 & 40 \\
\hline $\begin{array}{l}\text { General } \\
\qquad \begin{array}{l}\text { machin } \\
\text { ery }\end{array}\end{array}$ & $\begin{array}{l}-0.4219 \\
0.9524\end{array}$ & $\begin{array}{l}-4.4744 \\
2.6163\end{array}$ & Yes & 0.7802 & 40 \\
\hline $\begin{array}{l}\text { Electrical } \\
\qquad \begin{array}{l}\text { machin } \\
\text { ery }\end{array}\end{array}$ & $\begin{array}{l}6.2713 \\
1.3552\end{array}$ & $\begin{array}{l}5.6614 \\
3.7628\end{array}$ & Yes & 0.9002 & 40 \\
\hline $\begin{array}{r}\text { Transport } \\
\text { equip } \\
\text { ment }\end{array}$ & $\begin{array}{l}6.7060 \\
0.5024\end{array}$ & $\begin{array}{l}1.2685 \\
0.9336\end{array}$ & Yes & 0.8826 & 40 \\
\hline $\begin{array}{l}\text { Precision } \\
\text { instru } \\
\text { ments }\end{array}$ & $\begin{array}{l}4.32139 \\
0.8115\end{array}$ & $\begin{array}{l}-3.9460 \\
1.8107\end{array}$ & Yes & 0.7477 & 40 \\
\hline $\begin{array}{l}\text { Other } \\
\text { manufa } \\
\text { cturing }\end{array}$ & $\begin{array}{l}0.0655 \\
0.3824\end{array}$ & $\begin{array}{l}1.1179 \\
1.4888\end{array}$ & Yes & 0.5307 & 40 \\
\hline
\end{tabular}




\section{Table 7}

\section{Beta Coefficients for Goods with Significant Coefficients on IDIODEM}

Sector

Textiles

Iron and Steel

Paper and Pulp

Transportation Equipment

Non-Ferrous Metals

Electrical Machinery

Precision Instruments

Chemicals
Beta

Coefficient

0.82

0.40

0.51

0.74

0.42

0.37

0.42

0.53 
Figure 1

Production Distortion vs. Absorption Distortion

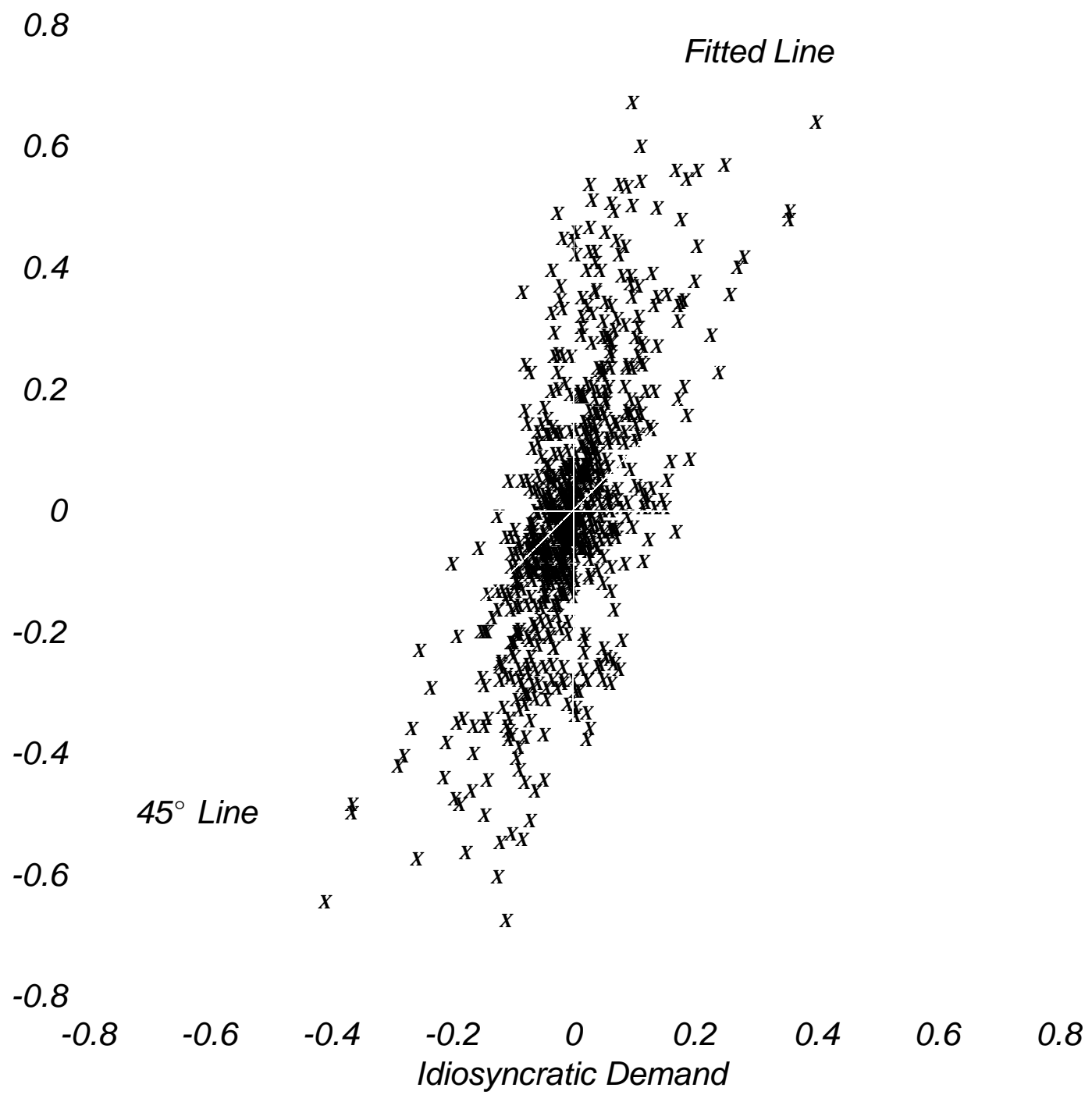


Figure 2

\section{Coefficient on IDIODEM vs. R\&D Intensity}

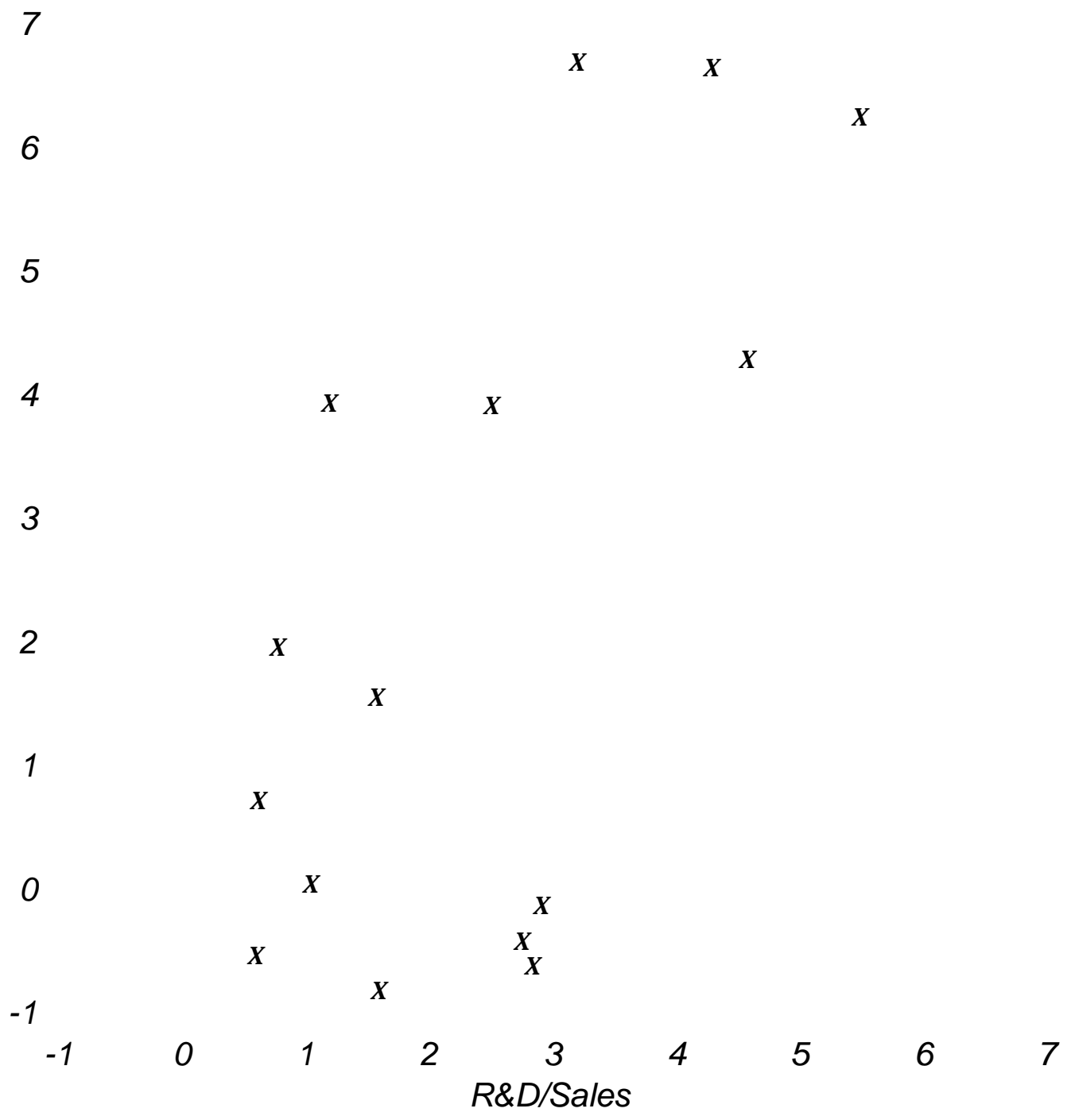




\section{DATA APPENDiX}

\section{Prefectural EndoWments}

The numbers of workers by educational attainment were entered by prefecture directly from the Employment Status Survey of 1987 (Shugyo Kozo Kihon Chosa Hokoku). The capital stocks were imputed from prefectural investment data. Japan's yearly Annual Report on Prefectural Accounts (Kenmin Keizai Keisan Nempo) give investment flows for each prefecture from 1975 to 1985 . These flows were used to impute capital stock levels for each prefecture in 1985, using capital goods price deflators from the Annual Report on National Accounts (Kokumin Keizai Keisan Nempo) and a rate of depreciation of 0.133 (This was the same rate of depreciation used by Bowen, Leamer, and Sveikauskas (1987)). Each year's flow was deflated using a capital deflator from the National Accounts.

\section{Prefectural Production}

The gross output of 20 manufacturing sectors in each prefecture was taken from the Japanese Census of Manufactures for 1985. The gross output of 9 non-manufacturing sectors in each prefecture was taken from the Prefectural Accounts for 1985. Finally, these totals were scaled so that the 47-prefectural total for each sector exactly matched the total Japanese output as reported in the 1985 Input-Output Table of Japan. Thus, in effect, the data from the Census of Manufactures and from the Prefectural Accounts was used in order to distribute total Japanese output for each sector across the 47 prefectures as accurately as possible.

\section{TECHNOLOGY}

Each element of the $3 \times 29$ technology matrix $\boldsymbol{B}$ was calculated by dividing Japanese total output for the 29 sectors into the number of each factor present in each sector. Most of the data on college and non-college workers in each sector came from the 1988 Wage Census (Chingin Sensasu). There were some gaps in this data as follows: 1) There was no data for college and non-college workers for agriculture, forestry, and fisheries or for government. These numbers were taken from the 1987 Employment Status Survey (Showa 63 Nen Shugyo Kozo Kihon Chosa Hokoku Chiiki Hen I II). 2) There was also no data for the petroleum/coal and leather industries. Total employment for each of these sectors was taken from the 1985 Census of Manufactures. The number of college workers per unit output for each was then imputed by assuming that petroleum/coal has the same fraction of college workers as the chemicals sector

and that leather has the same fraction as manufacturing overall. The capital stocks in each of the 
30 sectors were imputed from investment numbers, using the Annual Report of the Corporation Survey for non-manufacturing and the Census of Manufactures for manufacturing.

\begin{abstract}
ABSORPTION
Intermediate input use in each region was calculated using the Japan 30x30 IO matrix for 1985. Thus, INPUT $\boldsymbol{T}=\boldsymbol{A X}$, where INPUT is intermediate consumption in region $r, \boldsymbol{A}$ is the IO matrix, and $\boldsymbol{X}^{r}$ is gross output in region $r$. Both INPUT and $\boldsymbol{X}$, therefore, are 30x1 vectors. The 47 INPUT $\boldsymbol{T}^{r}$ vectors together form a 30x10 intermediate consumption matrix. It is important to note that one of our sectors in both $\boldsymbol{A}$ and $\boldsymbol{X}^{r}$ is producers of government services. Government absorption is therefore included in INPUT .
\end{abstract}

The construction of the consumption data was quite complex. In 1984, the Japanese government performed a detailed survey of Japanese consumption on the prefectural level, the National Survey of Income and Expenditure, that broke Japanese household consumption up into 65 categories. Unfortunately this data cannot be easily concorded into the 30 industrial Categories that we use in the paper. However the Economic Planning Agency does provide a 30x42 bridging matrix which map the 42 consumption commodities that can easily be formed from the 56 consumption categories in the Family Income and Expenditure Survey for 1987 into 30 core sectors corresponding to the Japanese IO table. Unfortunately this second source of data only reports information for ten Japanese regions. Since the 65 categories of the National Survey of Income and Expenditure did not always correspond to the 56 categories of the Family Income and Expenditure Survey, we used the following procedure to develop consistent series. First, for most categories there was a perfect match between the two sources, so we used the National Survey of Income and Expenditure for entries wherever possible. We then used regional totals scaled by household income shares to fill in the gaps. Since we were using both 1984 and 1987 data all prefectural entries were scaled so that they matched the regional totals.

This data was then aggregated up to 42 categories, producing a $42 \times 47$ matrix of final consumption by region. The survey data was based, of course, on consumer prices, so the bridge matrix was specially constructed to translate the consumption expenditure into producer prices. Most of the difference between consumer and producer prices results from wholesale and retail markups and from transportation costs, so the mapping shifted portions of spending on each final good into the wholesale/retail trade and transportation sectors, reflecting the fact that to consume anything bought retail is to consume the wholesaling, retailing, and transportation services which brought the product to the store. Without this adjustment, the data would have 
greatly underestimated final consumption of wholesale/retail and transportation services and would have shown each region exporting far more of these services than is plausible.

There are no investment figures broken down for 30 sectors and 47 prefectures, so these numbers were imputed using IO Table investment data. The IO Table breaks down investment into the 30 sectors for Japan as a whole. This vector was then distributed across regions, using as weights each region's share in total investment for Japan as a whole. Thus, $\boldsymbol{I N} \boldsymbol{V}^{\boldsymbol{r}}=$ $\left(T I^{r} / T I^{J}\right) \boldsymbol{I N} \boldsymbol{V}^{J}$, where $\boldsymbol{I N} \boldsymbol{V}^{r}$ is a 30x1 investment vector for region $r, T I^{r}$ is the total investment for that region in 1985 (taken from the prefectural accounts), $T I^{J}$ is Japan's total investment for 1985 , and $\boldsymbol{I N} \boldsymbol{V}^{\boldsymbol{r}}$ is the $30 \mathrm{x} 1$ investment vector taken from the IO Table. These $10 \boldsymbol{I N} \boldsymbol{V}^{\prime} \mathrm{s}$ therefore formed a 30x10 investment matrix. Business consumption was added to the data in a similar fashion. The data for all prefectures was then aggregated into 29 sectors to make it compatible with our $\boldsymbol{B}$ matrix.

\section{R\&D Data}

Research and Development data was taken from the Report on the Survey of Research and Develpment. 